\title{
Linguistic Input and Interaction in the Content Classroom ${ }^{1}$
}

Margaret Early

This study investigates teacher talk to different audiences of listeners and attempts to formulate a general description of the linguistic register particular to the classroom speech of ESL teachers. It describes and quantifies various features of classroom conversational interaction and various characteristics of ESL teachers' input to second language learners. It then investi- gates the degree to which the properties of foreigner talk in this corpus are representative, by comparing them to the results of Long's (1980) investigation of patterns of input and interaction outside of classrooms. Findings are summarized and a few cautious statements concerning the implications for the ESL classroom are made.

\section{INTRODUCTION}

In no special institution is communication more fundamental to its central purpose than in the school. The classroom dialogue between teachers and pupils constitutes, in our society, the educational process or at least the major part of it. Yet, until recently very little educational research has been based on direct observation and recording of the teaching process as it happens in the classroom. Most of the research in teacher-learner verbal interaction in classrooms has centered on investigation of the relationship between the teachers' methods on the one hand and their effectiveness, as measured by the learners' achievement, on the other. The most significant shortcoming of these earlier studies is that they avoided looking at the actual process of classroom discourse and the question of language variability in specific educational settings. This paper looks at the language of the classroom. Specifically, it looks at various features of teacher-talk in two distinct educational settings: the English as a Second Language (ESL) classroom and the regular native speaker classroom.

Long and Sato (1983, p. 170) suggest that the classroom speech of SL teachers "is probably a hybrid register characterized by features of both teacher-talk (Cazden 1979) and foreigner-talk (Ferguson 1975)". The present study is an investigation of that suggestion. The study examines teacher-talk with different listeners and attempts to formulate a general 
description of the linguistic register particular to the classroom speech of ESL teachers. Specifically, in addressing its aim, it seeks to do three things. First, it describes and quantifies various features of classroom conversational interaction between native speaker ESL teachers and students of ESL. Second, it describes and quantifies various characteristics of the speech addressed by ESL teachers to second language learners, i.e. the input. Third, it investigates the degree to which the properties of foreigner-talk (FT) in this corpus are representative, by comparing them with the results of Long's investigation of patterns of input and interaction outside the classroom (1980). The paper then concludes with a summary of findings and a few cautious statements concerning their implications for the ESL classroom.

\title{
PURPOSE
}

A review of the literature (see Long 1980; Early 1985) reveals that while the corpus of information on foreigner talk has increased steadily since Ferguson's (1975) article, there is, as Long (1980, p. 62) points out, "still a need for description of many aspects of linguistic input and interaction in SLA and for research on variables related to each." For, as he continues:

\begin{abstract}
After 15 years of study in this area there are surprisingly few data which have been derived from study of native speaker (NS) non-native speaker (NNS) and NS-NS interaction. Further, of the few studies which have provided NS control data, almost all have compared corpora which differ along one or more of the following sociolinguistic parameters: speech event, setting, tasks and kind of interlocutor.
\end{abstract}

Furthermore, only four (Chaudron 1979; Early 1985; Schinke-Llano 1983; Urzua 1980) of the FT studies to date are in kindergarten through high school settings. Thus, as Schinke-Llano states (1983, p. 146), "A major portion of the second language learners, namely those in the kindergarten through high school (K-12) setting, have yet to be considered in the literature". The purpose of this study is to seek data which addresses the following two general research questions:

(1) How do regular teacher with NS students and ESL teacher with NNS students classroom interactions differ in structure?

(2) What are the differences in features of linguistic input between regular teacher with NS and ESL teacher with NNS classroom talk?

\section{HYPOTHESES}

Twelve hypotheses were made related to the two research questions: 


\section{Research question (1)}

How do regular teacher - NS student and ESL teacher - NNS student classroom interactions differ in structure?

It is hypothesized that ESL teachers' speech in NNS classroom interaction will employ:

(1) different relative frequencies of questions, statements and imperatives in t-units

(2) different relative frequencies of Wh, Yes-No, uninverted intonation and tag questions in T-units

(3) more conversational frames

(4) more confirmation checks

(5) more comprehension checks

(6) more clarification requests

(7) more self-repetitions

(8) more repetitions of the interlocutors' utterances

(9) more expansions of the interlocutors' utterances

\section{Research question (2)}

What are the differences in features of linguistic input between regularteacher - NS and ESL teacher - NNS classroom talk?

It is hypothesized that ESL teachers' linguistic input will be less complex as indicated by:

(10) a shorter length of T-units in words

(11) a lower number of S-nodes per T-unit

(12) a lower type-token lexical ratio

\section{METHOD}

The data were collected in two large public high schools in Vancouver, British Columbia, Canada. Part or all of the proceedings of 16 lessons were tape recorded. These represent the verbal behaviours of 16 teachers providing instruction in a single subject (Social Studies) in two different educational settings (ESL and regular NS high school programs).

\section{(A) The ESL Classroom}

Subjects for the study were 8 experienced ESL teachers and their students. Each ESL teacher also had experience in teaching social studies. The students were taught English for specific purposes; they attend for 
example, English through Science classes, English through Social Studies, English through Physical Education and Home Economics classes as an integral part of their schooling. They spend only two blocks out of an eight-block schedule in English language classes per se. This approach is becoming increasingly common in ESL programs in Vancouver and is by no means unique to these particular schools. The content of the ESL classes taped was part of the English through Social Studies program. All teachers were teaching their regular class. Four of the classes were designated beginner and four were designated intermediate. The assignment of students to classes was relatively arbitrary, however, and all classes had, or so it seemed to the author, a mixture of beginner and intermediate students. Class sizes ranged from 15 to 20 with students from predominantly Cantonese, Punjabi and Vietnamese language backgrounds. Most had been in Canada less than a year. All had been in Canada less than two years. The classes were mixed in age, ability and previous education experience.

\section{(B) The Regular Classroom}

Subjects for this part were 8 experienced Social Studies teachers. Three teachers taught grade 8 Social Studies, three taught grade 9, and two taught the senior students (grades 11 and 12). All classes were highly integrated both racially and linguistically. All students were either NS or NNS fluent in their second language, English. Class sizes ranged from 25 to 33 .

\section{Data Collection}

In order to obtain a text, the observer (in all cases, the author) operated a small cassette tape recorder from a discreet position, usually the back of the room. As the researcher was known personally to all the teachers and many of the students, her presence did not seem to disturb the usual classroom routines. Teachers and students were told she was observing the class to help develop a curriculum for the ESL Social Studies program. All teachers were eager to co-operate. The only specification made to the teachers was that the lessons to be observed would have student-teacher interaction, not 50 minutes of seatwork. In some sessions the teachers talked non-stop for 50 minutes, while in others seatwork was assigned at short intervals throughout or at the end. The tapes ranged in length, therefore, from 30 to 45 minutes. 


\section{ANALYSIS}

\section{Definition}

Following Long (1980: 81-83) the following definitions were applied: conversational frames are boundary markers, such as well, so, ok, now which precede or follow utterances but which are not semantically related to that utterance; confirmation checks are any expression by the NS immediately following an utterance by the interlocutor which was designed to elicit confirmation that the utterance had been correctly understood or correctly heard by the speaker; comprehension checks are any expression by an NS designed to establish whether that speaker's preceding utterance has been understood by the interlocutor; clarification requests are any expression by a NS designed to elicit clarification of the interlocutor's preceding utterance; self repetitions are any repetition by the NS, either partial or complete, of any of his or her utterance(s) which occurred within five conversational turns of the turn containing the item now being repeated; other-repetitions are any repetition, partial or complete, exact or semantic, of speech by the interlocutor which occurred during the preceding five conversational turns by both speakers; expansions are any utterance by an NS which rephrased and/or repeated all or part of the interlocutor's preceding utterance and contained grammatical functions not supplied by the interlocutor in obligatory contexts created by the preceding utterance; average length of T-unit in words is the total number of words in T-units (Hunt 1966) divided by the total number of T-units; average number of s-nodes per $\mathrm{T}$-unit is the number of tensed verbs in T-units divided by the number of T-units containing them; type-token ratio is the number of words divided by the number of different words.

\section{Statistical Analysis}

Chi-square tests were performed on those of the above computations which resulted in proportional relative frequency data. Another nonparametric test, Mann-Whitneyu-Wilcoxon Rank Sum $W$ test, was employed for all other variables. Due to the fair number of tests being performed on the same corpus and the probability that five texts in one hundred would attain probability by chance, a probability level of .005 was set for rejection of the hypothesis.

\section{RESULTS}

The results are presented around the two research questions: 
Research question (1): How do regular teacher - NS students and ESL teacher - NNS students classroom interactions differ in structure?

$H \# 1$ : relatively different distributions of questions, statements and imperatives in T-units.

Table 1 shows percentages of questions, statements and imperatives in T-units in NS-NS and NS-NNS classroom conversations. The results show a significant difference in relative distributions of the three forms between the groups $\left(\chi^{2}=18.24, \mathrm{df}=2, \mathrm{p}<.001\right)$.

Table 1

Proportions of Questions, Statements and Imperatives in T-units in regular and ESL lessons.

\begin{tabular}{|l|cccc|}
\hline & $\mathrm{Q}$ & $\mathrm{S}$ & $\mathrm{I}$ & Total \\
\cline { 2 - 5 } & $\%$ & $\%$ & $\%$ & $\%$ \\
\hline $\begin{array}{l}\text { Regular } \\
\begin{array}{l}\text { Teacher- } \\
\text { NS Students }\end{array}\end{array}$ & 19.25 & 72.50 & 8.25 & 100 \\
\hline $\begin{array}{l}\text { ESL Teacher- } \\
\text { NNS Students }\end{array}$ & 30.01 & 51.42 & 18.57 & 100 \\
\hline \multicolumn{2}{|l}{$\begin{array}{l}\text { Questions } \times \text { Statements } \times \text { Imperatives } \\
\text { df }=2, \mathrm{p}<.001 .\end{array}$} & $\chi^{2}=18.24$ & \\
\hline
\end{tabular}

$H \# 2: \quad$ relatively different distributions of the four-question types in $T$ units.

Table 2 shows the percentages of four-question-types in T-units in NS-NS and NS-NNS classroom conversations. The results show that the distribution of question types did not differ significantly between the two groups $\left(\chi^{2}=1.49, \mathrm{df}=3, \mathrm{p}>.10\right.$ n.s. 
Table 2

Question-types in T-units in regular and ESL lessons.

\begin{tabular}{|l|ccccc|}
\hline \multirow{2}{*}{} & \multicolumn{5}{|c|}{ Question-Type } \\
\cline { 2 - 6 } & WH & yes-no & Inton. & Tag & Total \\
\cline { 2 - 6 } & $\%$ & $\%$ & $\%$ & $\%$ & $\%$ \\
\hline $\begin{array}{l}\text { Regular Teacher- } \\
\text { NS Students }\end{array}$ & 66.50 & 24.51 & 3.49 & 1.50 & 100 \\
\hline $\begin{array}{l}\text { ESL Teacher- } \\
\text { NNS Students }\end{array}$ & 68.48 & 23.55 & 6.45 & 1.52 & 100 \\
\hline & \\
WH $\times$ Yes-No $\times$ Inton. $\times$ Tag \\
$=\chi^{2}=1.49, \mathrm{df}=3, \mathrm{p}>.10 \mathrm{n}$. .s. \\
\hline
\end{tabular}

$H \# 3$ through H\#9: more conversational frames, more confirmation checks, more comprehension checks, more clarification requests, more self-repetitions, more otherrepetitions, and more expansions.

Table 3 shows the values for seven features of interaction in NS - NS and NS - NNS classroom conversation.

Table 3

Seven measures of linguistic interaction in regular and ESL lessons.

\begin{tabular}{|l|c|c|c|c|}
\hline & $\begin{array}{c}\text { Regular Teacher } \\
- \text { NS Students } \\
\overline{\mathrm{X}}\end{array}$ & $\begin{array}{c}\text { ESL teacher- } \\
\text { NNS Students }\end{array}$ & & \\
& 72.66 & 96.83 & 2.08 & .05 n.s. \\
\hline Conversational Frames & 0.63 & 0.17 & - & - \\
Confirmation Checks & 2.58 & 16.17 & 3.58 & .001 \\
Comprehension Checks & 0.17 & 0.00 & - & - \\
Clarification R'qsts & 14.00 & 56.41 & 3.84 & .001 \\
Self-Repetitions & 16.33 & 44.33 & 3.16 & .005 \\
Other-Repetitions & 0.92 & 12.41 & 3.52 & .001 \\
Expansions & & & $\mathrm{Z}$ & $\mathrm{P}<$ \\
\hline
\end{tabular}

It can be seen that four out of seven interaction variables attained significance at the .005 level or beyond. ESL teachers employed more comprehension checks $(Z=3.58, \mathrm{p}<.001)$, more self-repetitions $(\mathrm{Z}=$ $3.84, \mathrm{p}<.001)$, more other-repetitions $(Z=3.16, \mathrm{p}<.005)$ and more expansions $(Z=3.52, \mathrm{p}<.001)$ in their classroom conversations with NNS students than did regular teachers in their conversations with NS 
students. There was no difference in teachers' use of conversational frames between the two groups $(Z=2.08, p<.05$ n.s. $)$.

The observed frequencies of confirmation checks and clarification requests were too low to permit statistical analysis.

Research question (2): What are the differences in features of linguistic input between regular teacher - NS and ESL teacher - NNS classroom talk?

$H \# 10$ through H\#12: a shorter length of T-unit in words, a lower number of $S$-nodes per T-unit and a lower type-token lexical ratio.

Table 4 shows the values for three features of linguistic input in NS - NS and NS - NNS classroom conversation.

Table 4

Three measures of linguistic input in regular and ESL lessons.

\begin{tabular}{|l|c|c|c|c|}
\hline & $\begin{array}{c}\text { Regular Teacher } \\
- \text { NS Students } \\
\overline{\mathrm{X}}\end{array}$ & $\begin{array}{c}\text { ESL Teacher- } \\
\text { NNS Students } \\
\overline{\mathrm{X}}\end{array}$ & $\mathrm{Z}$ & $\mathrm{P}<$ \\
\hline $\begin{array}{l}\text { Average Length of } \\
\text { T-units in words }\end{array}$ & 11.01 & 6.96 & 3.81 & .001 \\
$\begin{array}{l}\text { Average Number of } \\
\text { S-nodes per T-unit }\end{array}$ & 1.51 & 1.18 & 3.75 & .001 \\
Type-Token Ratio & 37.00 & 35.10 & 2.67 & .01 n.s. \\
\hline
\end{tabular}

We see in Table 4 that two out of the three input variables attained significance at the required .005 alpha level. In ESL teachers' linguistic input to NNS students, the average length of T-units was shorter $(Z=$ $3.81, p<.001)$ and the average number of S-nodes per T-unit was lower $(\mathrm{Z}=3.75, \mathrm{p}<.001)$ than in regular teacher-talk to NS students. There was no difference in type-token ratio $(\mathrm{Z}=2.63, \mathrm{p}<.01 \mathrm{n} . \mathrm{s}$.) across the two conditions.

\section{DISCUSSION}

The first research question asks if there is a difference in conversational interaction in teacher-talk with NNS than with NS students. Of the nine hypotheses, five found support in the data. ESL teachers employed relatively different frequencies of questions, statements and imperatives than did regular teachers. They also employed more comprehension checks, more self-repetitions, more other-repetitions, and more expansions than 
regular teachers. There was no significant difference in the distribution of question-types in the teachers' talk across the two conditions or in teachers' use of conversational frames. Confirmation checks and clarification requests rarely occurred in the data from either classroom setting.

The second research question asks if there are differences in features of linguistic input to NNS students as opposed to NS students. Two of the three hypotheses found support in the data. The average length of T-unit in words and the average number of S-nodes per T-unit were found to be lower in teacher-talk to ESL students. Teachers employed shorter, syntactically less complex utterances when talking to NNS than to NS students. These findings are consistent with previous studies of teachers' talk to NNS students (Henzl 1979; Gaies 1977; Trager 1978; Chaudron 1979; Hyltenstam 1981; Early 1985). However, we learn that teachers do not use a restricted lexicon. There were no examples of ungrammatical teachertalk found in the data.

Clearly, then, there is foreigner-talk in the ESL classroom. Teachers, when working with NNS students, employ syntactically shorter and less complex utterances and make a lot of adjustments to the interactional structure of their classroom conversations. There are several possible reasons for teacher FT, among which are: teachers seeking to accommodate the limited English proficiency of their students and teachers seeking to help their students learn English. Research on syntactic adjustments made in teacher FT is, at the present time, not sufficient to say why it is done, but this is a fruitful area of investigation.

This study also indicates that there are features of conversation where teachers do not make adjustments to the interactional structure of their classroom conversations. One of these features is the distribution of teachers' question-types. As Table 6 shows, Wh-questions were considerably higher in both classroom conditions $(67 \%$ and $68 \%$ for NS - NS and NS - NNS classrooms respectively) than the other three question-types. This finding is consistent with a previous study of interrogatives in teacher-talk to NS students (Kluwin 1977) which showed that most teacher questions were introduced by $W h$-words. In the present study, the function of these Wh questions, in both conditions, appears to be to answer display questions (i.e. questions which oblige students to display knowledge rather than to provide unknown information or express attitudes (Mehan 1979)) that require the students to label items, actions or agents. This has yet to be subjected to statistical analysis, however. Yes/No was the next most frequent question-type employed by ESL and regular teachers ( $25 \%$ and $28 \%$ respectively). Uninverted intonation ( $4 \%$ and $6 \%$ for ESL and the regular teachers respectively) and tag questions ( $2 \%$ for each setting) were seldom used in either condition. It may well be that questioning behaviour is strongly entrenched in the role (and/or 
particular teaching style) of teachers and varies less in relation to student variables than do other features of input and interaction. Other features of conversational interaction not adjusted by teacher in their talk across the two student groups are their use of conversational frames, confirmation requests and clarification requests.

Long (1983) points out that confirmation checks and clarification requests are among the interactional resources available to NSs to repair the discourse when it breaks down. Comprehension checks are among the devices available to avoid breakdowns. Self- and other-repetition may be used for avoiding and repairing trouble. An examination of teachers' use of self- and other-repetitions in this study indicates that these features were used for avoidance rather than repair purposes. Teachers across conditions go to a great deal of trouble to maintain control of conversation and avoid breakdowns. The significant findings for differences in comprehension checks, self- and other-repetitions in ESL teacher-talk indicate that teachers, when talking to NNS students, go to even more trouble to avoid conversational breakdowns. Presumably both groups are so successful with their avoidance strategies that the need to repair breakdown seldom occurs in classrooms. Absence of repair devices, then, (presumably as a result of frequent use of trouble avoidance strategies) is a feature of teacher-talk which is less affected by student variables than are other features of teachers' conversations. Finally, teachers across settings did not differ in their type-token ratios. ESL teachers do not appear to restrict their lexicon in this way.

This study has provided a general description of the linguistic register particular to the classroom speech of ESL teachers. We now turn to a comparison of the differences between the way ESL teachers use FT and the way FT is used outside the classroom. Specifically, we address the following question: How do the characteristics of ESL teachers' speech as modified input to the classroom learner, and the ESL teacher-student conversational interaction differ from the characteristics of linguistic input and interaction in conversations between NS and NSSs outside of classrooms?

This question is discussed by comparing the results of Long's study of NS - NS and NS - NNS interactions (1980) with the results of the study reported here.

It is acknowledged, in addressing this question, that Long's (1980) study differs from the present study in several ways including the fact that Long's data were derived from one-on-one conversations, between nonacquaintances, working with two-person communication tasks. This study's data were derived from chalk-talk, i.e. one to many conversations, between well-acquainted interlocutors, working on learning tasks. No firm conclusions will be drawn or definitive statements made. Rather it is 
hoped that a discussion of the findings of these two studies will raise some interesting issues and thus contribute to our knowledge of second language acquisition both in and out of classrooms.

The following measures common to both studies will be discussed: the relative distribution of questions, statements and imperatives in T-units, the relative distribution of question-types in T-units, conversational frames, confirmation checks, comprehensive checks, clarification requests, self-repetitions, other-repetitions, expansions, mean length of $\mathrm{T}$-unit in words, average number of S-nodes per T-unit and type-token lexical ratio.

In both studies the relative frequencies of questions, statements and imperatives differ significantly in NS - NS and NS - NNS conversations: Long's results are: questions $\times$ statements $\times$ imperatives $\left(\chi^{2}=62.12, \mathrm{df}=\right.$ $2, \mathrm{p}<.001$ ); as reported above (Table 1), the results of this study are: questions $X$ statements $X$ imperatives $\left(\chi^{2}=18.24\right.$; $\left.\mathrm{df}=2, \mathrm{p}<.001\right)$. It should be noted, however, that in both NS - NS and NS - NNS classroom conversations the absolute frequency of imperatives (8\% and 19\% NS NS and NS - NNS conversations respectively) is markedly higher than either NS - NS or NS - NNS conversations (2\% and $3 \%$ respectively) outside of classrooms. The absolute frequencies of questions and statements did not vary so markedly.

The more frequent use of imperatives in teacher-talk to both groups can be accounted for by the power and status vested in the role of teacher. This role engages them in management and disciplinary functions where commands encoded as imperatives are frequently used. While this accounts for the more frequent use of commands in as opposed to out of classrooms, it does not explain ESL teachers' more frequent use of imperatives. An examination of the data shows that it can be hypothesized that ESL teachers use imperatives more frequently as part of the teaching process (e.g. "Point to Ottawa on your map." "Look at Figure 1.") than do regular teachers. They appear to involve students in more action-oriented, context-embedded learning acts. To date, however, this hypothesis has not been subjected to statistical computation.

Next we compare Long's results and this study's results for the distribution of four question-types in NS - NS and NS - NNS conversations in and out of classrooms.

Long (1980) reports that NS - NS and NS - NNS conversations out of classrooms differ significantly in their distribution of question-types $\left(\chi^{2}=\right.$ 16.77, $\mathrm{df}=3, \mathrm{p}<.001)$. However, as shown earlier in this paper, NS - NS and NS - NNS conversations in classrooms do not $\left(\chi^{2}=1.49, \mathrm{df}=3, \mathrm{p}<\right.$ .10 n.s.).

The finding that teachers do not use question-types differently from NS outside classrooms is interesting. Not only are the statistical findings 
different across the two corpora but the absolute distribution of questiontypes is quite different in conversations in and out of classrooms. It seems that whereas $W h$-questions predominate in ESL instruction (68\%), yesno questions are the most frequent type of question (43\%) in NS - NS conversations outside of classroom. As stated earlier, Wh-questions are frequent in teacher-talk (Kluwin 1977); it appears ESL teachers conform to this pattern in their questioning behaviour in using large numbers of $W h$-questions. NSs outside of classroom, however, choose a less linguistically demanding type of questioning-behaviour in the form of yes-no questions presumably in an attempt to make things easier for the NNS.

We move next to a comparison of Long's findings with those reported earlier in the paper for seven measures of linguistic interaction. For ease of comparison, the findings are summarized and presented in Table 5.

Table 5

Seven measures of linguistic interaction in conversations in and out of classrooms.

\begin{tabular}{|c|c|c|c|c|c|c|}
\hline & \multicolumn{3}{|c|}{ Long's (1980) findings } & \multicolumn{3}{|c|}{ Early's present findings } \\
\hline & NS-NS & NS-NSS & & NS-NS & NS-NNS & \\
\hline & $\overline{\mathrm{X}}$ & $\overline{\mathrm{X}}$ & $\mathbf{P}<$ & $\overline{\mathrm{X}}$ & $\overline{\mathrm{X}}$ & $P<$ \\
\hline $\begin{array}{l}\text { Conversational } \\
\text { Frames }\end{array}$ & 85.10 & 81.00 & n.s. & 72.66 & 96.83 & $.05 \mathrm{n} . \mathrm{s}$ \\
\hline Confirmation Checks & 3.83 & 22.92 & .005 & 0.63 & 0.17 & - \\
\hline $\begin{array}{l}\text { Comprehension } \\
\text { Checks }\end{array}$ & 4.09 & 18.15 & .005 & 2.58 & 16.17 & .001 \\
\hline $\begin{array}{c}\text { Clarification } \\
\text { Requests }\end{array}$ & 1.83 & 10.35 & .005 & 0.17 & 0.00 & - \\
\hline Self-Repetitions & 5.97 & 41.86 & .005 & 14.00 & 56.41 & .001 \\
\hline Other-Repetitions & 6.67 & 15.09 & .005 & 16.33 & 44.33 & .005 \\
\hline Expansions & 0.00 & 5.8 & .005 & 0.92 & 12.41 & .001 \\
\hline
\end{tabular}

Of the seven interactional devices compared, five have similar findings. In both studies, comprehension checks, self-repetitions, other-repetitions and expansions are found to be significantly different. Conversational frames are found to be non-significantly different in both studies.

If one looks at the frequencies across the two corpora it can be seen that teachers' talk to NS students employs not only fewer conversational frames than to NNS students, but fewer conversational frames than either NS - NS or NS - NNS interactions outside of classrooms. This is noteworthy in that conversational frames have been reported in the literature 
as features of teacher-talk (Heath 1978). A comparison of conversations in and out of classroom does not support this notion. In fact, it suggests that although boundary markers are indeed pervasive in teacher-talk, teachers may actually use fewer boundary markers in conversations in NS classrooms than in other NS settings.

Confirmation checks and clarification requests were significantly different in Long's (1980) study of foreigner talk whereas they seldom appear in ESL teachers' speech. This indicates a greater need to repair conversational breakdowns in informal conversations than in teacher-talk in classrooms. Teachers' superior status in conversation more readily permits them to control the conversation and thus avoid rather than repair breakdowns.

Finally, we move to a comparison of the findings for three measures of linguistic input in and out of classrooms. In both studies, the average length of T-units is found to be significantly different in NS - NNS interaction. In classroom conversations the average length of S-nodes is found to be significantly different in teachers' speech to NNS than to NS students. This measure is not found to be significantly different in NS - NS and NS - NNS interaction outside classrooms. Perhaps teachers' greater familiarity with their interlocutors encourages them to make greater syntactic adjustments in their linguistic input. In both studies no difference is found in measures of lexical type-token ratio.

Of importance is the question of differences in conversational interaction and modified linguistic input in NS - NNS conversations in and out of classrooms. ESL teacher-talk in this study is similar to FT as reported by Long (1980) in the following ways: both are marked by a relatively different distribution of questions, statements and imperatives, by more comprehension checks, more self-repetitions, more other-repetitions, more expansions and a shorter average length of T-unit in words. ESL teacher-talk and FT also differ in several ways: FT had a different distribution of question-types and a higher frequency of confirmation checks and clarification requests than NS - NS interaction in informal conversation; ESL teacher-talk and regular teacher-talk did not differ in these features. ESL teacher-talk had a lower number of S-nodes per T-unit than regular teacher-talk; NS - NS and NS - NNS informal conversations did not differ in these features. Both studies showed no difference in frequency of conversational frames or in type-token ratio in NS - NS and NS - NNS conversations.

What are the ostensible contributions to our knowledge of NS - NNS conversations made by this study?

First of all, the study detected clear and strongly-marked differences between teachers' linguistic input to NNS and to NS students. Since the findings of previous studies of teachers' syntactic adjustments to less 
proficient listeners are contradictory, the significant differences which were discovered lend solid support to the hypothesis that teachers adjust the complexity of their speech downwards when talking to students with limited English proficiency.

We now turn to interaction measures which have been studied less frequently than measures of input. The study detected clear and stronglymarked differences between teachers' linguistic interaction with NNS and NS students. Since this is one of the few studies of modified interaction which has quantified the data and compared findings with NS - NS conversations, the significant differences which have been uncovered are important. This study's findings not only support Long's (1980) findings that NSs modify their linguistic interactions when addressing NNSs but extend his findings to a quite different situation - the classroom.

This study also speaks to the input/interaction distinction which is most clearly reflected in the contrast between the view of Krashen (1982) and the view of Long $(1980,1981,1983)$.

Finally, the study uncovered some similarities and some differences in FT in and out of classrooms. These will be discussed in the conclusion section and some implications will be drawn for classroom practice.

\section{CONCLUSION}

The research reported here was an exploratory study which attempted a) to describe and quantify various features of classroom conversational interaction and modified linguistic input in ESL teacher-talk to SL learners and b) to investigate the degree to which the properties of ESL teacher-talk reported here are representative of FT in general by comparing them to previously established patterns of input and interaction outside the classroom as reported by Long (1980).

From this limited and partial analysis of ESL teacher-talk it is possible to draw certain tentative conclusions. Before doing so, however, several limitations of this study must be pointed out. First, the data were derived from teachers' speech in a formal classroom setting; findings may not, therefore, be generalizable to other classroom conditions (e.g. informal, small group or individualized). Second, the data were collected from one subject area and two schools. The findings may not be generalizable either to other subject-areas or to other schools. Third, no consideration was given to variation in teacher-talk related to either task or teaching-style. Fourth, the age range is limited to teacher-talk to adolescents and young adults. Fifth, several relevant linguistic measures (e.g. stress of keywords, topic-comment construction, deixis and pronominalization) are not discussed. Sixth, the sample size is small and there are a fair number of variables. This limits the power of the analysis. 
Bearing in mind the limitations stated above, and the need for more data-based research on teacher-talk, certain tentative conclusions may be drawn.

Clearly, there is a difference in the linguistic environment of ESL and regular classes. ESL teachers modify both the interactional structure and the syntactic complexity of their speech to accommodate the limited English proficiency of their students. They do so by employing relatively different frequencies of questions, statements and imperatives, more comprehension checks, more self-repetitions, more other-repetitions, more expansions, a shorter average length of $\mathrm{T}$-unit in words and a loweraverage number of S-nodes per T-unit.

While it is not yet empirically shown, it is widely assumed that at least some of these measures of modified input and adjustments to the interactional structure of conversation facilitiate successful SLA. The findings of this study show that comprehensible input as inferred from measures of these characteristics are more accessible to the SL learner in the ESL than in the regular classroom.

The comparison of NS - NNS conversations inside and outside classrooms revealed similarities and differences in their structure. In both studies NS - NNS conversations had a relatively different frequency of questions, statements and imperatives than NS - NS conversations. In both studies, a higher frequency of comprehension checks, selfrepetitions, other-repetitions and expansions and a lower average number of words per T-unit was found in NS - NNS than in NS - NS conversations. Both studies reported non-significant differences in the use of conversational frames. ESL teachers and FT also differ in several ways. Teachers do not employ a different distribution of question types in NS NS than in NS - NNS conversations; NSs outside of classrooms do. Teachers seldom use comprehension checks and clarification requests in either NS - NS or NS - NNS classroom conversations; NSs in conversations outside of classrooms use these measures frequently and significantly differently from NS - NS interactions. ESL teachers use a lower number of S-nodes per T-unit than do regular teachers. Long's (1980) findings did not show significant differences in these variables.

When discussing a comparison of NS - NNS conversation inside and outside classrooms, one must exercise caution in stating even the most tentative implications for classroom practice. With this in mind a few cautious statements will be made concerning the implications of this study for the NNS classroom.

First is the issue of teachers' questioning behaviour. The results of this study indicate a fairly restricted use of question types in the ESL classroom as opposed to NS - NNS conversations outside of classrooms. Table 6 illustrates this. 
Table 6

Questioning Behaviours

Outside Classrooms

(Long 1980)
Inside Classrooms

(Early 1985)
Wh

Yes-No

Intonation

Tag
$24 \%$

$43 \%$

$28 \%$

$5 \%$
$68 \%$

$24 \%$

$6 \%$

$2 \%$

As can be seen in Table 6, the SL classroom learner has limited exposure to intonation and tag questions and since intonation questions, in particular, are relatively frequent $(28 \%)$, and certainly more frequent than Wh-questions (24\%), outside of classrooms, this leads one to consider how well teachers' questioning behaviour prepares the student for life outside the classroom. Further, while practice in $W h$-questions is obviously necessary for English specific to classrooms (see Table 2), clearly yes-no questions, because they a) predominate in conversations outside of classrooms and b) are linguistically less demanding on students, merit more attention in ESL classes. Although interesting exploratory work has been done by Long \& Sato (1983), far more work on both forms and functions of teachers' questions is needed to establish just how critical these issues are to SLA.

The use of interactional devices bears comment also. ESL teachers work very hard to make meaning clear to students by their frequent use of trouble avoidance devices. Few opportunities are available to the students to repair breakdowns and to negotiate for meaning. Yet it may be through this very type of interaction that some internalization of the linguistic system may come to the students. The debate on this continues. In the meantime it is imperative that teachers do not deny the students opportunities to interact in these particular ways.

In summary, it appears that ESL teachers do provide a different lingustic environment for NNS students than do the regular teachers. This ESL teacher-talk, which is similar in some ways to FT outside of classrooms, is also distinctly different in some important ways from NS - NSS conversations outside of classrooms. Further research is needed to determine if indeed, as one suspects, the differences in both directions, i.e. from teacher-talk and from FT, are important, and, if this is the case, how the teacher's behaviour and methodological approaches might be changed accordingly. The crucial research on this question is still to be done. In the interim, what can be suggested to ESL teachers who are in programs which aim both for the learning of language and the learning of content? 
First, ESL teachers should not necessarily model themselves on their colleagues who teach content to native speakers, at least with respect to classroom interaction patterns. Second, ESL teachers should be careful not to limit their students' language opportunities. They must be sure to plan for activities which not only allow but actually promote opportunities for students to interact and negotiate for meaning. And these activities should encourage interaction and negotiation across as wide a range of language contexts and functions as possible.

\section{FOOTNOTE}

1. The author would like to thank Lee Gunderson for his help with the statistical analyses, and Richard Day, Mike Long, Bernie Mohan and the anonymous TESL-Canada Journal reviewers for their helpful comments on earlier versions of this article.

\section{REFERENCES}

Cazden, C. (1979). Language in education: variation in the teacher-talk register. In J. Alatis and R. Tucker (Eds.). Language in Public Life. Washington, D.C.: Georgetown University Press.

Chaudron, C. (1979). Complexity of teacher speech and vocabulary explanation/elaboration. Paper presented at the 13th Annual TESOL Convention, Boston, Massachusetts.

Chaudron, C. (1983). Foreigner Talk in the classroom - an aid to learning? In $\mathrm{H}$. Selinger and M. Long (Eds.). Classroom Oriented Research in Second Language Acquisition. Rowley, Mass.: Newbury House.

Early, M.M. (1985). Foreigner Talk and Teacher Talk in Content Classrooms: A Study of Input and Interaction. Ph.D. dissertation, University of California at Los Angeles.

Ferguson, C.A. (1975). Towards a characterization of English Foreigner Talk. Anthropological Linguistics, Vol. 17, 1-14.

Gaies, S. (1977). The nature of linguistic input in formal second language learning: linguistic and communicative strategies in teachers' classroom language. In H.D. Brown, C.A. Yorio and R. Crymes (Eds.)., On TESOL '77. Teaching and Leaming English as a Second Language: Trends in Research Practice. Washington, D.C.: TESOL.

Heath, S.B. (1978). Teacher-talk language in the classroom. Language in Education: Theory and Practice, No. 9. Arlington, Va.: Center for Applied Linguistics.

Henzl, B.M. (1979). Foreigner talk in the classroom. International Review of Applied Linguistics, 17(2), 159-167.

Hunt, K.W. (1981). Recent measures in syntactic development. Elementary English, Vol. 43 (November), 732-739.

Hyltenstam, K. (1981). Teacher talk in Swedish as a second language classrooms: quantitative aspects and markedness conditions. Paper presented at the conference on Interdisciplinary Perspectives of Language Acquisition Research. University of Passau. 
Kluwin, T. (1977). A Discourse Analysis of the Language of the English Classroom. Ph.D. dissertation, Stanford University.

Krashen, S.D. (1982). Principles and Practice in Second Language Acquisition. Oxford: Pergamon Press.

Long, M.H.(1980). Input, Interaction and Second Language Acquisition. Ph.D. dissertation, University of California at Los Angeles.

Long, M.H. (1983). Native speaker/non-native speaker conversation and the negotiation of comprehensible input. Applied Linguistics 4, 126-141.

Long, M.H., and C.J. Sato. (1983). Classroom foreigner talk discourse: forms and functions of teachers' questions. In H.W. Seliger and M.H. Long, (Eds.) Classroom Oriented Research in Second Language Acquisition. Rowley, Mass.: Newbury House.

Mehan, H. (1979). "What time is it, Denise?": asking known information questions in classroom discourse. Theory into Practice 18, 4, October.

Pica, T. and M.H. Long. (1982). The classroom linguistic and conversational performance of experienced and inexperienced teachers, Paper presented at the 16th Annual TESOL Convention, Honolulu, Hawaii.

Schinke-Llano, L.A. (1983). Foreigner talk in content classrooms. In H. Seliger and M.H. Long (Eds.). Classroom Language Acquisition and Use: New Perspectives. Rowley, Mass.: Newbury House.

Trager, S. (1978). The Language of Teaching: Discourse Analysis in Beginning, Intermediate and Advanced ESL Students. Unpublished M.A. Thesis, University of Southern California.

Urzua, C. (1980). Language input to young second language learners. Paper presented at the Second Language Acquisition Forum, University of California at Los Angeles.

\section{THE AUTHOR}

Margaret Early is an Assistant Professor in the Language Education Department, University of British Columbia. She was previously the Provincial Coordinator of ESL Programs in B.C. Currently, she is co-director with Bernie Mohan of a large-scale Vancouver School Board project to improve the academic achievements of ESL students. 